\title{
The Effect of Gamma Ray $(\gamma)$ Irradiation on Optical Absorption of Polymer Film Blend
}

\author{
Ni Nyoman Sri Putu Verawati \\ Physic Education Department, Universitas Mataram, Indonesia \\ *Corresponding Author Email: veyra@unram.ac.id
}

\section{Article History}

Received: November 2020

Accepted: December 2020

Published: December 2020

\section{Key Words}

Gamma ray irradiation; optical absorption; polymer film

\begin{abstract}
Polymer films have become a material for research recently because polymer films have an important role in the application of basic sciences. The polymer film has good mechanical, electrical and optical properties to be used in many applications, one of which is a polymer film that has the potential to be irradiated into a dosimeter. Therefore, modification of polymer film one of which is gamma ray irradiation is important to be further explored. This study aims to explore the effect of gamma ray irradiation on the optical absorption of polymer film blend PVA (polyvinyl alcohol) -trichloroacetid acid (TCA) methylene blue (MB). Preparation of polymer films by chemical processes using the solvent-casting method. Each polymer film was irradiated with gamma rays with radiation doses ranging from $0 \mathrm{kGy}$ to $14 \mathrm{kGy}$. Optical absorption was measured using a UV-VIS spectrophotometer with a range of wavelengths ranging from $200 \mathrm{~nm}$ to $700 \mathrm{~nm}$. The results showed that three optical absorption peaks were formed on the polymer film PVA-TCA-MB due to gamma ray radiation at wavelengths of $360 \mathrm{~nm}, 440 \mathrm{~nm}$, and $560 \mathrm{~nm}$. Gamma ray radiation has an effect on optical absorption, where the optical absorption value of polymer film for the first peak $(360 \mathrm{~nm})$ and second peak $(440 \mathrm{~nm})$ decreased along with the increase in the dose of gamma ray irradiation, but for the third peak $(560 \mathrm{~nm})$ there was an increase in the optical absorption value along with an increase in the dose of gamma ray irradiation. The results of further studies are described in this article.
\end{abstract}

How to cite this article?

Verawati, N., N., V. (2020). The Effect of Gamma Ray $(\gamma)$ Irradiation on Optical Absorption of Polymer Film Blend. Lensa: Jurnal Kependidikan Fisika, 8(2), 48-54. doi:https://doi.org/10.33394/j-1kf.v8i2.3215

\section{INTRODUCTION}

Gamma radiation is electromagnetic radiation emitted by excited nuclei during the process of falling to a lower energy level. Gamma rays are short electromagnetic waves with high energy (Fadli et al., 2018). A common source of gamma radiation is Cobalt-60 (Isaacs, 1990). The physical, chemical and biological properties of the material can be modified by treatment by ionizing radiation in the form of gamma rays. This radiation technique has become very important in material processing technology for now when compared to traditional chemical processes. Natural and artificial polymers have been irradiated by ionizing radiation to modify their mechanical properties, material structure, optics and electrical properties for a wide variety of applications such as dosimeters and electro-chemistry, optical and electrical devices (Chmielewski \& Haji-Saeid, 2004; Cleland et al., 2003). The reaction process that occurs can be through cross-linking, homopolymerization and grafting and at the same time this irradiation process will produce a sterile product (Verawati, 2012).

Polymer films have become a material for research recently because polymer films have an important role in the application of basic sciences. The polymer film has good mechanical, electrical and optical properties to be used in many appliance applications, one of which is a polymer film that has the potential to be irradiated into a dosimeter 
(Dutta et al., 2001). Dosimeter film is one of the topics in radiation technology that has attracted a lot of attention from both researchers, health practitioners and industry circles due to its wide scope of use and suitability of its characteristics (Akhtar et al., 2016). Dosimeter film is a detector that is light, easy to carry (portable) and can be placed in various locations (Bhat et al., 2007). This instrument in the form of film is widely used because of its ruggedness, stability of long storage life, reliability, ease of handling, can be produced on a large scale, and the price is relatively cheaper (Akhtar et al., 2013).

The working principle of this dosimeter film is a change in color when the film is exposed to ionizing radiation, such as exposure to electron beams and gamma rays (Ebraheem et al., 2002), x rays (Butson et al., 2010), and ultaviolet rays (Abdel-Fattah et al., 2000). Dosimeter film can be developed from polymer-based materials and dye indicators. The basic polymers that can be used include polyvinyl alcohol (PVA) (Bhat et al., 2007; Akhtar et al., 2013), polycarbonate (PC) (Galante \& Campos, 2012), polyvinyl chloride (PVC) (Kattan \& Daher, 2016), and polyvinyl butyral (PVB) (Abdel-Fattah et al., 2000). The combination of the polymer base material selection and the dye indicator produces a polymer film that can change color when exposed to radiation. The modification of the two materials, not only changes the color of the polymer, but the chemical and optical properties of the polymer film can also change, depending on the application.

After radiation, the polymer film will undergo a shift in optical absorption indicating a low energy bandgap. After irradiation, the polymer film mixed with the dye can be investigated for its optical properties, which can be used for the development of optical devices. Modification of optical properties can mean improving the reflectance or absorption or interference properties of these optical devices (Khopkar, 1990). Further research is needed to investigate other mixtures of organic matter which can undergo changes in optical properties such as existing dosimeters.

Polyvinylalcohol (PVA) is the polymer used in this study. PVA is widely used in industrial goods because it has good mechanical strength, high tensile strength and is electrochemically stable. PVA contains a carbon chain with a hydroxyl group attached to a metankarbon. The $\mathrm{OH}$ group becomes a source of hydrogen bonding which helps form the polymeric mixture of PVA (Rajendran et al., 2004). PVA which is added with color and organic mixture containing chlorine is a material that is sensitive to radiation and can change color, if it is irradiated there is a formation of acid and a decrease in the $\mathrm{pH}$ of the material so that it can act as a dosimeter (Abdel-Fattah et al., 2000). Polyvinyl alcohol is water soluble, slightly soluble in ethanol, but insoluble in other organic solvents. Solutions with $5 \%$ polyvinyl alcohol showed a $\mathrm{pH}$ in the range 5.0 to 6.5 . Polyvinyl alcohol has a melting point of from $180^{\circ} \mathrm{C}$ to $190^{\circ} \mathrm{C}$. The molecular weight of polyvinyl alcohol is between 26,300 and 30,000 , and a degree of hydrolysis of $86.5 \%$ to $89 \%$ (Saxena, 2004).

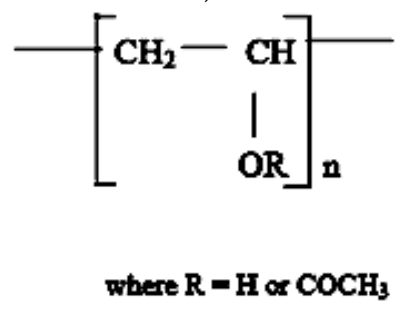

Figure 1. Simple structure of polyvinyl alcohol

The aim of this study was to investigate the effect of $\gamma$-ray irradiation on the polymer film blend of PVA (polyvinyl alcohol), TCA (trichloroacetid acid) and MB (methylene blue) on the optical absorption value. Trichloroacetic acid is an analogy of acetic acid where three hydrogen atoms from the methyl group are replaced by chlorine atoms and 
have a basic form $\left(\mathrm{CCl}_{3} \mathrm{COOH}\right)$, while methylene blue is an indicator of acid-base whose color changes when the $\mathrm{pH}$ of the solution changed. The novelty of this study is that polymer film blends are treated in an unusual way by irradiating gamma rays to change their optical properties which is the focus of this study.

\section{METHOD}

This study is an experimental research conducted in a laboratory. Preparation of polymer films by chemical processes using the solvent-casting method. The process of making polymer films used $3.5 \mathrm{gr}$ PVA, $1 \mathrm{~g}$ TCA, $0.08 \mathrm{~g} \mathrm{MB}, 50 \mathrm{ml}$ ethanol, and 10\% $\mathrm{NaOH}$. First, mixed methylene blue, ethanol, and $\mathrm{NaOH}$ to make polymer dyes. PVA was dissolved using $100 \mathrm{ml}$ distilled water in a beaker. The solution mixture is then heated using a heater at $80^{\circ} \mathrm{C}$ and stirred using a magnetic stirrer. Heating at this temperature is carried out until the volume remains $50 \mathrm{ml}$, after about 15 minutes $1 \mathrm{~g}$ of TCA is added while stirring using a magnetic stired. After the TCA is evenly distributed, the dye is added to the solution mixture while stirring at $20^{\circ} \mathrm{C}$ until the solution is homogeneous. The homogeneous solution was poured into a petri dish and let stand for five days. After five days the solution solidifies which is called the polymer film. The polymer film was removed from the petri dish using tweezers then cut into sizes of $2 \mathrm{~cm} \times 2 \mathrm{~cm}$. The polymer film that has been cut is then irradiated with gamma rays $(\gamma)$ with various doses (doses 0 $\mathrm{kGy}$ to $14 \mathrm{kGy}$ ). The optical properties of the polymer film were irradiated (optical absorption rate) for each radiation dose using a UV-VIS spectrophotometer with a wavelength range from $200 \mathrm{~nm}$ to $700 \mathrm{~nm}$.

The data that has been obtained is then analyzed to calculate optical absorption (A), with the formulation:

$$
A=\log \frac{I_{0}}{I}
$$

Where $I_{0}$ and $I$ are the intensity of the incident and reflected rays, $A$ is the optical absorption value (Pudjaatmaka, 1994).

\section{RESULTS AND DISCUSSION}

The effect of gamma ray $(\gamma)$ radiation on the optical properties of the polymer film PVA-TCA-MB has been investigated and measured using a Uv-Visible (UV-VIS) spectrophotometer. When observed from the color aspect, the mixed polymer PVA-TCA$\mathrm{MB}$ changes color from purplish blue to light blue (slightly yellow) along with the increase in radiation dose (Figure 2). The UV-VIS measurement results of the polymer film are presented in Figure 3, where the absorption spectrum produces three peaks, each one in the UV light region and two peaks in the visible light area.

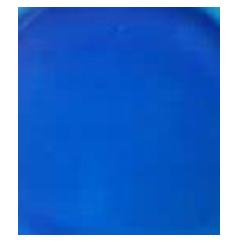

$0 \mathrm{kGy}$

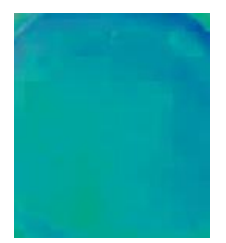

8 kGy

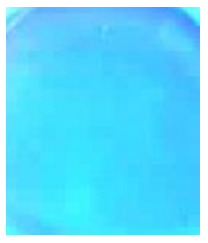

$12 \mathrm{kGy}$

Figure 2. Changes in polymer color with the addition of $\gamma$-ray irradiation dose 


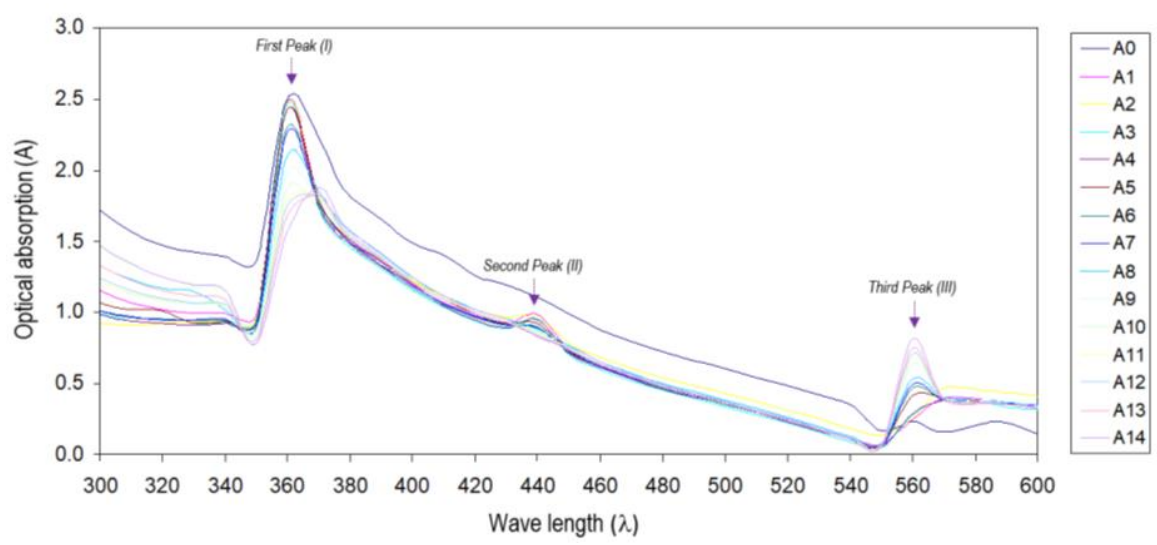

Figure 3.The relationship between optical absorption (A) and wavelength $(\lambda)$

From the measurement results of PVA-TCA-MB polymer film samples with different radiation doses, the maximum absorption values were at a wavelength of $360 \mathrm{~nm}$ for the first peak, $440 \mathrm{~nm}$ for the second peak and $560 \mathrm{~nm}$ for the third peak for all radiation doses. If presented in graphical form, the relationship between radiation dose and optical absorption for the wavelengths of $360 \mathrm{~nm}$ (first peak), $440 \mathrm{~nm}$ (second peak) and $560 \mathrm{~nm}$ (third peak) are shown in Figure 4, Figure 5, and Figure 6.

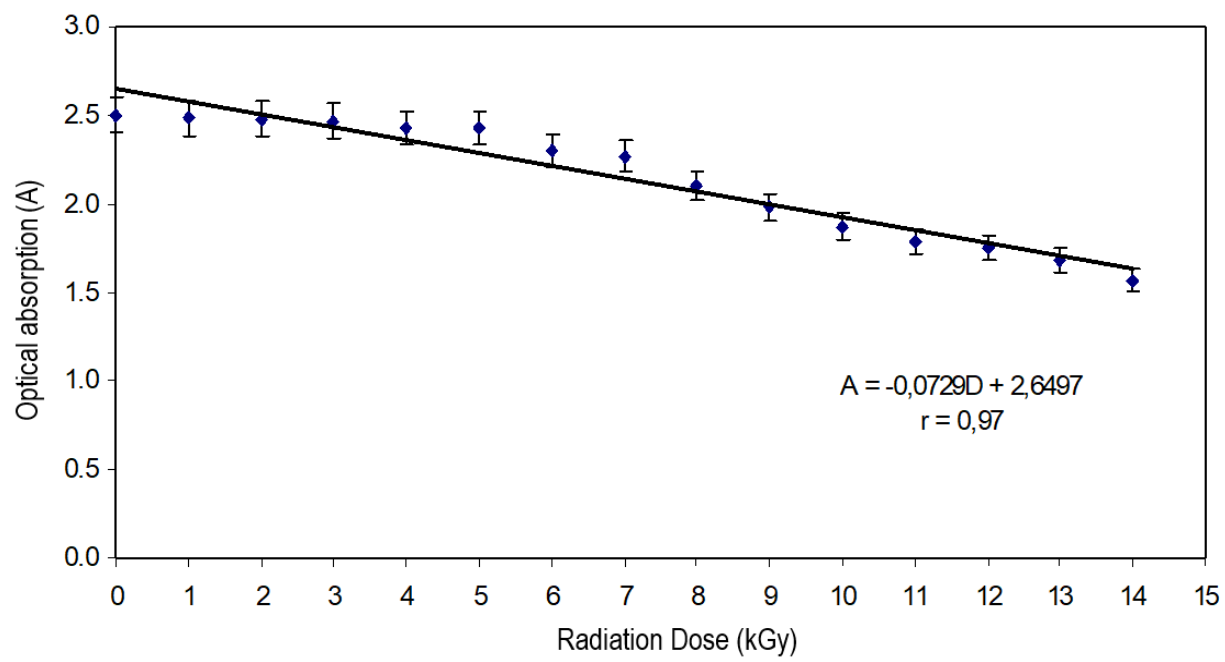

Figure 4. Relation of radiation dose (kGy) with optical absorption (A) for $\lambda=360 \mathrm{~nm}$ (first

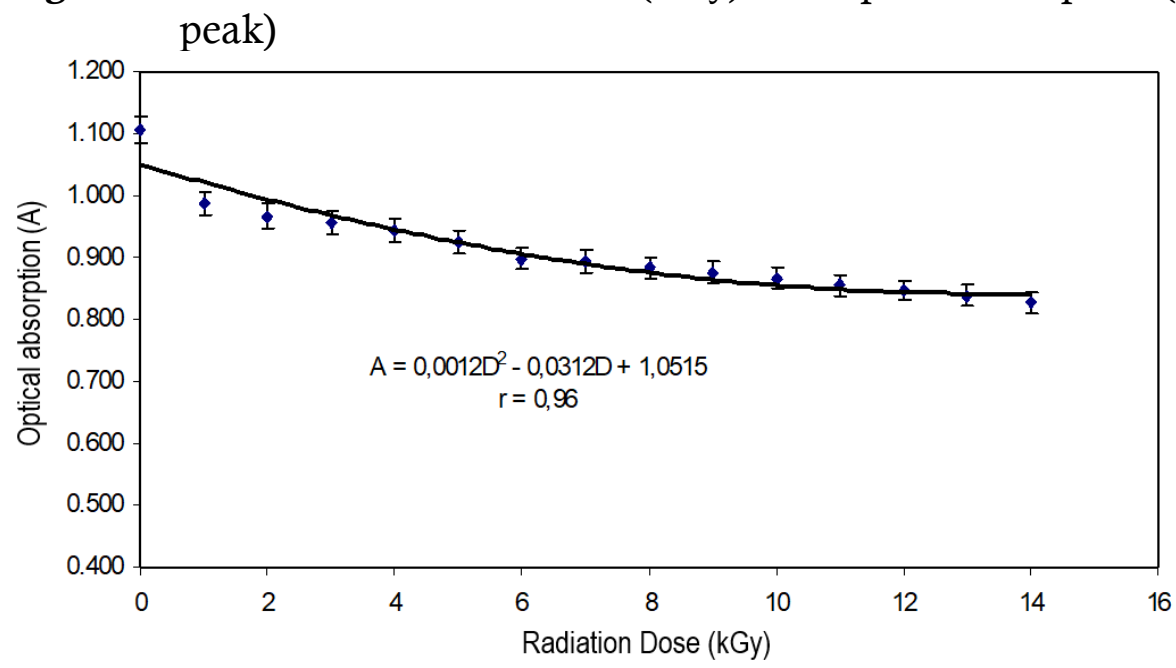

Figure 5. Relation of radiation dose (kGy) with optical absorption (A) for $\lambda=440 \mathrm{~nm}$ (second peak) 


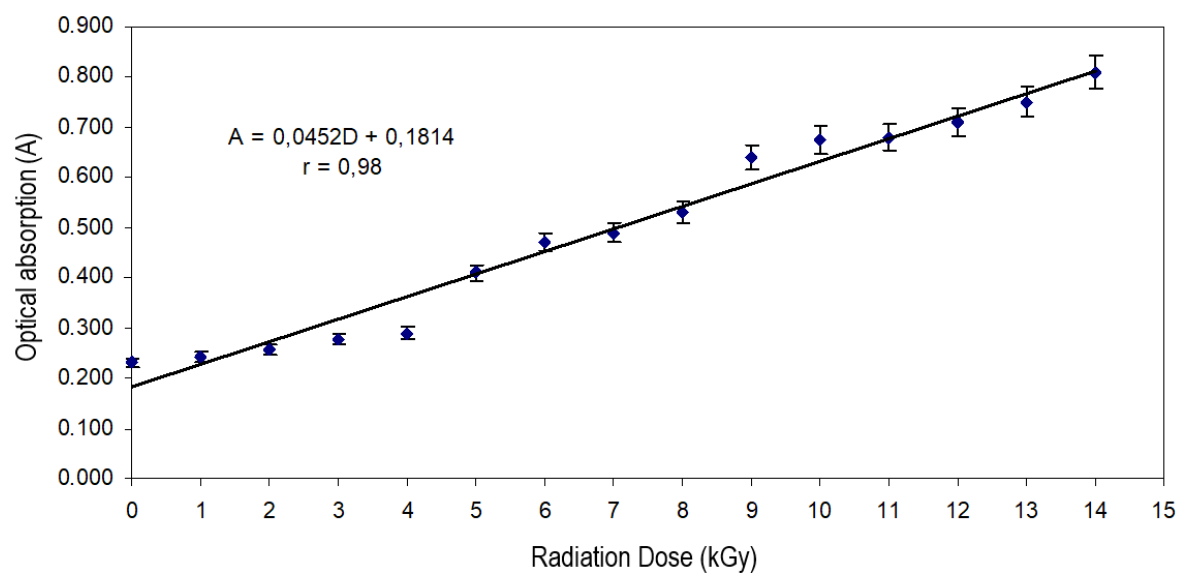

Figure 6. Relation of radiation dose (kGy) with optical absorption (A) for $\lambda=560 \mathrm{~nm}$ (third peak)

The absorption dosimeter of the material is in the $360 \mathrm{~nm}$ absorption area where this area is the UV light area, for $\lambda=440 \mathrm{~nm}$ it shows the absorbed blue color and the color that appears yellow, while for $\lambda=560 \mathrm{~nm}$ it shows the absorbed color is greenish yellow and the color that appear purplish blue. Color is one of the criteria for identifying an object in a spectroscopic analysis and the electromagnetic radiation spectrum is used to analyze chemical species and study their interactions with electromagnetic radiation. The maximum optical absorption produced shows the color absorbed by the PVA-TCA-MB polymer film.

From the results of the optical absorption data analysis for the first peak on the polymer film PVA-TCA-MB, an average decrease with the increase in radiation dose (Figure 4) given by the equation $\mathrm{A}=-0.0729 \mathrm{D}+2.6497$ in the form of linear regression with a correlation value $r=0.97$ in the very strong category, and at high doses of 12,13 and $14 \mathrm{kGy}$ there was a shift in optical absorption to $370 \mathrm{~nm}$. The second peak gives the results given by the equation $\mathrm{A}=0.012 \mathrm{D} 2-0.0312 \mathrm{D}+1.0515$ in the form of polynomial regression with a correlation value of $r=0.96$ with a very strong category (Figure 5), and for the third peak at $\lambda=560 \mathrm{~nm}$ there is an increase in the optical absorption value along with the increase in radiation dose with the linear regression equation $\mathrm{A}=0.0452 \mathrm{D}+$ 0.1814 with a correlation value of $r=0.98$ with a very strong category (Figure 6).

The absorption peak in the UV light region at $\lambda=360 \mathrm{~nm}$ decreases with increasing dose, this area is used to study optical characteristics. This absorption peak indicates the excitation of the outer electrons which provides information on electron transitions between molecules in the mixture of materials. The absorption peak in the UV light region at $\lambda=360 \mathrm{~nm}$ is the main cause of the transition of electrons (anions) from the valence band to the conduction band, representing the transition $\pi-\pi *$ from donor atoms (highest occupied molecular orbital) to acceptor atoms (lowest unoccupied molecular orbital) where this type of transition occurs in organic molecules and a small portion of organic anions. These molecules absorb electromagnetic radiation due to the presence of valence electrons which are excited to a higher energy level, as a result of radiation causing structural damage to the polymer mixture by the radiation breaking from the polymer mixture (Saion, 2005).

The optical absorption value decreases with the addition of the dose of gamma ray radiation at each wavelength $(\lambda) 360 \mathrm{~nm}$ and $440 \mathrm{~nm}$, and an increase in wavelength $(\lambda)$ $560 \mathrm{~nm}$ ). From the graph (Figure 1) it can be seen that there is a change in color from PVA-TCA-MB samples from purplish blue to yellow, blue in MB indicates alkaline and 
yellow indicates acidic conditions This color change indicates the formation of strong acids, with an increase in radiation dose, many chlorine ions break from the TCA carbon chain and due to radiation causes ions $\mathrm{H}+$ and $\mathrm{OH}$ - become free radicals resulting from the hydrolysis of water from the sample molecules, then they combine in acidic form, by lowering the $\mathrm{pH}$ of the polymer mixture.Previous studies have reported the effect of gamma radiation on PVA-TCA mixtures measured using Raman spectroscopy, for the intensity distribution of the molecular vibration distribution of the $\mathrm{C}-\mathrm{Cl}$ strain bond of the TCA. During gamma ray irradiation the TCA will ami dehydrochlorination, which raises chlorine ions in the polymer film. The hydrocarbon derivative of the halogen as in this case, namely the $\mathrm{C}-\mathrm{Cl}$ bond is more radiosensitive than the $\mathrm{C}=\mathrm{O}, \mathrm{C}-\mathrm{C}$, or $\mathrm{C}-\mathrm{OH}$ bond from TCA (Susilawati, 2009). The strain distribution of TCA decreased with increasing radiation dose $\gamma$ (Susilawati \& Doyan, 2009).

The findings in this study are also similar to the findings of previous researchers. PVB polymer film containing chloral hydrate and bromophenol blue (BPB) dye has shown stable dosimeter properties, for a long time this dosimeter changes color from blue to green to yellow after being irradiated by UV light which indicates a change from BPB in acidic form, the blue color of bromophenol blue indicates alkaline properties and the yellow color shows acidic properties with the highest dose up to $9 \mathrm{kGy}$ with a maximum optical absorption band at wavelengths of 421 and $601 \mathrm{~nm}$ using a spectrophotometer (AbdelFattah et al., 2000). PVA polymer film containing chloral hydrate material with cresol red dye (PVA-CH-CR) irradiated with $\gamma$ rays has been studied with gamma ray radiation doses from $0 \mathrm{kGy}$ to $13 \mathrm{kGy}$, the PVA-CH-CR film polymer underwent a color change from yellow at $438 \mathrm{~nm}$ optical absorption peak to red with optical absorption peak at 529 $\mathrm{nm}$, where at the first peak $(438 \mathrm{~nm})$ decreased optical absorption with an increase in radiation dose and at the second peak experienced an increase in optical absorption with increasing radiation dose, indicating the formation of acid in polymer blends, due to the interaction of $\gamma$ radiation with the polymer causes dehydrochlorination of $\mathrm{CH}$ to form acid and reduce the $\mathrm{pH}$ level of the film mixture (Susilawati \& Doyan, 2015).

\section{CONSLUSSION}

The results of this study indicate that three optical absorption peaks have been formed on the PVA-TCA-MB polymer film due to gamma ray radiation $(\gamma)$, namely at 360,440 , and $560 \mathrm{~nm}$. Gamma ray radiation affects the optical absorption value, namely; a) Optical absorption for the first peak $(360 \mathrm{~nm})$ on average decreased along with the increase in radiation dose given by the equation $\mathrm{A}=-0.0729 \mathrm{D}+2.6497$ in the form of linear regression with a correlation value of $r=0.97$ with a very strong category; $b$ ) optical absorption for the second peak $(440 \mathrm{~nm})$ decreased along with the increase in radiation dose given by the equation $\mathrm{A}=0.012 \mathrm{D} 2-0.0312 \mathrm{D}+1.0515$ in the form of polynomial regression with a correlation value of $r=0.96$ with a very strong category; and c) at the third peak $(560 \mathrm{~nm})$ there was an increase in the optical absorption value along with the increase in radiation dose with the linear regression equation $\mathrm{A}=0.0452 \mathrm{D}+0.1814$ with a correlation value of $r=0.98$ in the very strong category.

\section{RECOMMENTATION}

In order to be applicable in many applications including electronic devices, it is not sufficient to present the results of the optical properties test but also to test the electrical properties. Therefore, the researchers suggest that further studies be carried out to explore the electrical properties of polymer film blends, for example the properties of electrical conductivity, dielectricity, and others. 


\section{ACKNOWLEDGMENTS}

This research received no specific grant from any funding agency in the public, commercial, or not for profit sectors.

\section{REFERENCES}

Abdel-Fattah A A, El-Sayed A, Hegazy H, \& El-Din E. (2000). Thymol-blue dyed poly (vinyl butyral) films for monitoring ultraviolet radiation, Journal of Photochemistry and Photobiology A: Chemistry 137, 37-43.

Akhtar, S., Shahzad, A., Bashir S, Hussain M Y, Akhtar, N \& Kang Z. (2016). Improved performance of radiochromic films for high dose dosimetry. Radioprotection, 129-133.

Akhtar S, Hussain T, Shahzad A, \& Islam Q. (2013). The feasibility of reactive dye in PVA films as high dosimeter. Basic \& Applied Sciences, 420-423.

Bhat N V, Nate M M, Bhat R M, \& Bhatt B C. (2007). Effect of $\gamma$ irradiation on polyvinyl alcohol films doped with some dyes and their use in dosimetric studies. Indian Journal of Pure \& Applied Physics 45, 545-548.

Butson M J, Yu P K N, Cheung T, \& Alnawaf H. (2010). Energy response of the new EBT2 radiochromic film to X-ray radiation. Radiation Measurements, 45(7), 836-839.

Chmielewski A G, \& Haji-Saeid M. (2004) Radiation technologies: Past, present and future Radiation Physics and Chemistry 71, 16-20.

Cleland M R, Parks L A, \& Cheng S. (2003). Application for radiation processing of materials. Nuclear Instruments and Methods in physics research section B 208, 66 -73.

Dutta P, Biswas S M, Ghosh S K, \& Chatterjee S. (2001). The DC and AC conductivity of polyaniline-polyvinyl alcohol blends, Synthetic Metals, 122, 455-461.

Ebraheem S, Eid S, \& Kovacs A. (2002). A new dyed poly (vinyl alcohol) film for highdose applications. Radiation Physics and Chemistry 63, 3-6.

Fadli N, Syarif Z, Satria B, \& Akhir N. (2018). The effect of gamma cobalt-60 ray irradiation on cultivar growth in taro white (Xhanthosoma Sagittifolium L.) International Journal of Environment, Agriculture and Biotechnology 3(6), 2020-2025

Galante A M, \& Campos L L. (2012) Mapping radiation fields in containers for industrial $\gamma$-irradiation using polycarbonate dosimeters. Appl Radiat Isot, 70(7), 1264-6.

Isaacs A. (1990). Kamus lengkap fisika. Jakarta: Erlangga.

Kattan M, \& Daher Y. (2016). The use of polyvinyl chloride films dyed with methyl red in radiation dosimetry. International Journal Radiation Research, 14(3), 263-267.

Khopkar S M. (1990). Konsep dasar kimia analitik. Jakarta: UI-Press.

Pudjaatmaka H. (1994). Kimia analisis kuantitatif anorganik. Jakarta: Penerbit Buku Kedokteran EGC.

Rajendran S, Sivakumar M, \& Subadevi R. (2004). Investigation on the effect of various plasticizers in pva-pmma solid polymer blend electrolytes. Materials Letters, 58, 641649.

Saion E. (2005). Changes in the optical band gap and absorption edge of gamma-irradiated polymer blends. Journal of Applied Sciences 5(10), 1825-1829.

Saxena S K. (2004). Polyvinyl Alcohol (PVA) (Chemical and Tehnical Assesment, FAO).

Susilawati \& Doyan A. (2009). Dose response and optical properties of dyed poly vinyl alcohol-trichloroacetic acid polymeric blends irradiated with gamma-rays. American Journal Of applied Sciences 6(12), 2071-2077.

Susilawati \& Doyan A. (2015). Effects of gamma radiation on electrical conductivity of PVA-CH composites. Materials Science Forum 827, 180-185.

Verawati N N S P. (2012). Serapan optik polimer film PVA-TCA-MB yang diradiasi sinar gamma. Pijar MIPA VI (2), 60-64. 